\title{
Research on Improving the Technological Innovation Capability of SMEs by University-Industry Collaboration
}

\author{
Daqi XU" \\ ${ }^{I}$ Dept. of College of Management Engineering, Anhui Polytechnic University, Wuhu, 241000, China
}

Received 15 May 2013; Accepted 25 July 2013

\begin{abstract}
The innovative resource of SMEs themselves is very limited, resulting in low technological innovation capability. The reasons of low technological innovation capability were analyzed. In addition, the mechanism of improving the technological innovation capability of SMEs by University-Industry collaboration was explored from several following sides: enhancing enterprise learning capacity, speeding up the flow of information, the internalization of external talents, realizing the innovation resource sharing and so on. The conclusion of this paper has great significance to UniversityIndustry Collaboration and enhances their innovation capability.
\end{abstract}

Keywords: U-I Collaboration, Small and Medium-sized Enterprises (SMEs), Technological Innovation Capability, Improvement

\section{Introduction}

A country's economic strength is reflected in the market and international competitiveness of enterprises, whose strength or weakness depends on the value-added products, that is to say, depends on the technological innovation capability of enterprises. China's scientific and technological resources, technical personnel and scientific research achievements are mainly concentrated in universities, research institutes and government departments, while SMEs lack these resources. At the same time, the conversion rate of China's scientific and technological achievements is relatively low, only about $15 \%$ and the contribution rate of technological progress on economic growth is far below the level of developed countries, only $29 \%[1]$. Therefore, we must vigorously carry out industry-university-research cooperation, which can effectively resolve such problems as the lack of technology, human resources, information and technological innovation capability of SMEs accounting for more than $99 \%$ of the total number of enterprises, accelerate the transformation of scientific and technological achievements of universities and research institutes, and promote industrial upgrading and technological progress.

\section{Cause analysis of low technological innovation capability of SMEs}

\subsection{Conservative operating thinking and lack of innovative consciousness}

SMEs are generally operating a smaller asset thin with weak technology base and poor ability to prevent and control risks. For the sake of safety and security, as long as their

*E-mail address: cskyeah@ziu.edu.cn

ISSN: 1791-2377 @ 2013 Kavala Institute of Technology. All rights reserved. products have market and they can survive, enterprises will usually adopt an evasive attitude toward risky technological innovation. Compared with this, SMEs are more keen on the introduction or imitation of technology, thinking that the introduction and imitation has the advantage of less investment, direct effectiveness and low risk, and that carrying out technological innovation is involved in greater investment, time-consuming and highly risky, and that R \& $\mathrm{D}$ is the thing of the universities, research institutes or large enterprises. SMEs will import or imitate the techniques as long as necessary. They even believe that as long as they can fight for government support, banks' understandings, tax incentives, they will be able to survive and develop through simple and expanded reproduction and can still get a higher profit with no technical innovation or very little innovation. This business philosophy is just for survival and security, no considering of taking the risk to grow, only to see the immediate benefits regardless of the long-term goal, which leads to their staying the svelte, attaching no importance to technological innovation and lacking innovative spirit.

\subsection{Lack of environment and mechanisms to attract and retain innovative talent}

Compared with large enterprises, research institutes and universities, SMEs have a big gap in such respects as firm size, working environment, research conditions, social status, personal development prospects, and lack such effective incentive measures as technology shares and revenue sharing, which makes SMEs less attractive to excellent creative talents. Some enterprises, on the other hand, adopting the usual "brought on by" human resources strategy and lacking strategic vision, do not attach importance to the training, development and reserves of personnel; besides technical personnel in such enterprises lack exercising space and opportunity, which result in a lot of brain drain and SMEs having little talent for technological 
innovation. According to statistics, less than $10 \%$ of the SMEs employees have a college education [2]. Even if some SMEs do not lack the core technical personnel, also have a high level of expertise, and bear the main task of the research and development, but the total amount of corporate $\mathrm{R} \& \mathrm{D}$ personnel are less and most of them play several roles so in resolving some of the key technical problems, they can not take advantage of the "external forces" and "brain" and can not get the interdisciplinary technical support necessary[3], which makes it difficult to promote the technological innovation of enterprises.

\subsection{Limited access to funding sources and no guarantee to technological innovation}

SMEs, due to less fixed assets, low profit margins, relatively backward management and operational mechanism, coupled with lack of pledged assets and credit guarantees and other factors, have more difficulties in obtaining financing, venture capital, bank loans than large enterprises much, which result in their insufficient innovative capital investment. The research shows that nearly $70 \%$ of technological innovation funds is raised mainly by the owner, and the partner's personal savings or loans from relatives, friends, and accessed from the private lending, and that each year only $5 \%-8 \%$ of SMEs can obtain bank loans[4]. SMEs with conditions to seek direct financing listed on the SME board, the GEM or offshore are rare, and funds received from the government for technological innovation activities is also very limited. In addition, there also exists the time dislocation of capital supply and demand, and at the critical period of technical innovation, muchneeded loans can not be obtained a bit; when the fund is in place, the chances are lost. Owing to the lack of funds needed for technological innovation, production research and development can not be carried out, outstanding researchers can not be hired, and the production and marketing of new products are more difficult to be ensured.

\subsection{Over-reliance on the simple introduction and lack of technology accumulation}

With too much attention to the immediate benefits, SMEs are more willing to directly introduce the technology for the production of mature products. After the introduction of technology, they focus only on the study of knowledge of the maintenance and operation of the equipment, do not attach importance to the introduced technology's digestion and absorption, improvement and re-innovation, therefore, technological innovation has always been no qualitative improvement. Passive introduction of technology puts enterprises into the "introduction - use - backward reintroduction" vicious cycle, rendering the enterprises into no mastering the core technology and the lack of technical reserves to support long-term development. On the other hand, the simple introduction of mature technology makes a large number of enterprises rely on the same "Technical Sources", which makes them lack their own professional and technical characteristics and have no competitiveness. As a result, it is more difficult for the companies to form a competitive advantage in the market, which will lead to inter-enterprise homogenization, intensive low vicious price competition, and the impossible accumulation of technology. Limited resources for innovation and poor innovation collaboration

2.5 Limited resources for innovation and poor innovation collaboration
Technological innovation is involved in the process from idea generation, research and development, test, production, sales. It is a common thing for SMEs, in the process of technological innovation, to feel powerless in certain link or some aspects or lack certain resources. Although SMEs are closely linked to market and have a high degree of sensitivity in market dynamics and demand, but they have disadvantages in the knowledge, talent, technology, information, and other aspects of the development, not to say to solve the problems of technological innovation market failures. For a long time, there is lack of trust among enterprises, universities, research institutes, government departments. SMEs lack necessary conditions and awareness to establish strategic alliances, participate in the virtual organization, integrate the industrial clusters, and even the transformation of the scientific and technological achievements will be obstacles, they would like to pass the buck to each other on the key link - pilot study, all of which result in the failure to innovate; technology and information communication between enterprises, and between enterprises and other cooperation bodies are less and their collaborative links are weak. They does not establish the corresponding specialization division of labor, and not reach the effect of $1+1>2$, which makes technological innovation costs increased and its risk increased.

\section{Industry-university-research cooperation enhancing the mechanism of technological innovation capability of SMEs}

Technological innovation capability refers to the ability of relying on technological innovation to promote enterprises' development, that is, through the introduction or development of new technologies, to enable enterprises to meet or create market demand, to enhance the competitiveness of enterprises. Technological innovation activities typically rely on the cooperation of a number of different areas of knowledge, so that few organizations have all the necessary knowledge and technical personnel various resources needed for their technological innovation. Through industry-university-research cooperation to carry out technological innovation, resources, technology, personnel and other advantages of the different subjects can be combined, SMEs can take advantage of disciplines, talents, knowledge and information of universities and research institutes to solve technical problems faced in the technological innovation and crack the resource bottlenecks of technological innovation.

\subsection{Industry-university-research cooperation enhancing enterprises' learning ability and promoting fast knowledge transfer}

Technological innovation capability is an integral part of the technical capacity, in essence, is the knowledge [5]. The amount of various knowledge reserves has a direct impact on the level of technological innovation capability. Knowledge necessary for technological innovation usually has the characteristics of uniqueness, complexity and system, including explicit knowledge as well as a lot of tacit knowledge, which makes its transfer a certain viscosity. Learning can not only obtain and amplify knowledge resources, but also can promote the accumulation and application of knowledge, make tacit knowledge and explicit knowledge converted, reduce the viscosity of knowledge transfer, make knowledge spread and sublimated. The 
effectiveness and efficiency of learning is relevant not only to the human resources, the stock of knowledge, knowledge structure, corporate culture, but also to the participation of the learning process, the external conditions and environment.

SMEs, universities and research institute co-operate together, research and develop technology, carry out the test, convert results, discuss problems. The more frequent contacts and exchanges greatly enhance their liaison, communication and mutual trust, which is not only conducive to the spread and proliferation of explicit knowledge, but also enhances the tacit knowledge dissemination and diffusion. The rapid flow of tacit knowledge further promotes the flow and diffusion of explicit knowledge; learning outcomes and learning ability is greatly enhanced; acquiring innovative ideas and learning new technologies have become relatively easy. Knowledge transfer enables SMEs to obtain external technical expertise, to change the original stock of knowledge, to integrate this knowledge into their own systems or change their configuration to adapt to the new knowledge. It's brought a range of specialized, secret knowledge beyond any language, text, graphics and by innovative application, it is "materialized" in the company's products and services, forming the enterprises' specific knowledge base and technological capabilities and improving the overall quality and competitiveness.

3.2 Industry-university-research cooperation accelerating the flow of information to enable enterprises to timely access to technological innovation

The nature of technological innovation is the organic combination of technology and market. In the process of technological innovation, enterprises must collect and study a lot of technical information and market information concerning the formation of innovative ideas, prototype, test model, industrial prototype development, trial production, market development, product sales. Enterprises' technological innovation can also be viewed as the information processing process carried around the uncertainty of technological innovation to solve a series of problems in the process of technological innovation by access to information and its analytical processing. Enterprises must try every possible efforts to obtain fast, high-quality and comprehensive access to the information concerning technology, market, product and policy required for technological innovation, enhance the capability of identifying and applying the technological innovation information, understand and give insight into the latest technological developments and direction of development of domestic and foreign competitors, so that enterprises can scientifically develop appropriate technological innovation strategy, carry on the rapid development of new products, new technologies, improve production technology and the success rate of technological innovation so as to enhance the technological innovation capability of SMEs.

Industry-university-research cooperation brings enterprises, universities and research institutes together, increases its information channels, reduces the differences between the main body of the cooperation in the values and organizational culture, increases the strength of information communication, and promotes the optimal combination and effective utilization of information. In the phase of decision making, R \& $\mathrm{D}$, design, prototype, production, implementation of technological innovation, all the parties concerned share the latest information on technological developments, designing parameters, market supply and demand, exchange the product's appearance, quality, safety, marketing knowledge and methods as well as users' feedback and information on new products. This will broaden the enterprises' horizons, enhance the enterprises' vision, make up for enterprises' disadvantages, and improve enterprises' knowledge building capacity and market competitiveness [6].

\subsection{Industry-university-research cooperation making external talents internalized and effectively mitigating the deficiencies of technological innovation talent}

Innovative talent is the soul of enterprises' technological innovation activities. Without a certain quantity and quality of innovative talents, technological innovation is impossible. SMEs must take a variety of ways and different channels to relieve the present situation of lack of innovative talents. First, enterprises should fully exploit the innovation potential innovation within the enterprise, establish the flow mechanism of internal personnel training, provide a broad space for staff development, and organically combine the future development of the individual employees and enterprises' development goals. Enterprises can list the technology, management, and achievements as the factors of production to participate in the distribution, implement rewarding system to reward the technological innovative talents who have made outstanding contribution to enterprises, carry out technological innovation, retain existing talents and attract talented people at home and abroad to participate in the technological innovation activities; Second, SMEs should establish the multifarious, multi-level view of talent, adhere to the balance of "talent introduction and intellectual introduction" and try to establish the "not for me, but for me" employment ideas, make effective use of external human resources. With sound mechanism of introducing high-end talents, preferential treatment and free environment, enterprises should introduce the advanced talents with true skill, genuine knowledge and innovative capability, allow and encourage scientific and technological achievements owners to choose the right beneficial way in the achievement transformation, assure the innovative talents peace of mind to be engaged in enterprises' technological innovation [7].

Universities and research institutes in certain areas of expertise have gathered large number of experts and professors with outstanding scientific research ability, whose advantage enterprises can not be matched with. Making good use of the human resources of universities and research institutes is an effective way for enterprises to carry on technological innovation and enhance their own technological innovation capability. During the industryuniversity-research cooperation, technology transfer and commissioned development are ways to make direct use of innovative human resources of universities and research institutes; for technical personnel of enterprises and experts, professors of universities and research institutes come together to research, discuss, overcome difficulties in the process of jointly researching and developing new products and new technologies, which, on the one hand, makes the research capabilities of universities and research institutes internalized, on the other hand, makes the research and development ability of enterprises' technical personnel raised. In addition, enterprises can hire the scientific and technical personnel of universities and research institutes as the technical consultants or technical guidance, who can 
avail themselves of their spare time to participate in the innovation activities of SMEs; enterprises can not only send their technical staff to colleges and universities or research institutes for training or further study to improve their R \& D level and ability.

\subsection{Industry-university-research cooperation making the innovative resources shared and the risk of technological innovation reduced}

Due to the impact of institutional mechanisms, China's scientific research is long separated from enterprises and the market. Scientific research in universities and research institutes are separated from enterprises' actual needs. The value judgment of scientific and technological achievements is also inconsistent, the former emphasizing the academic value, the latter emphasizing the market value. Although SMEs have a flexible mechanism, a strong awareness of the market, available project funding, and a strong desire to apply new technologies, long-term low-level technology and expansion are its main development characteristics. Their production technology and equipment are relatively backward and their own resources are very limited. Universities and research institutes have strong basic science and technology, research and development capabilities and a lot of scientific research with market prospects, but do not have transformation conditions owing to lack of capital and market [7]. So they also have the desire to cooperate with enterprises. Cooperative innovation makes independent cooperation bodies form a community in the form of sharing main resources or complementing advantages. Improvement of the efficiency of resource allocation inside or outside the community's, directly or indirectly, generates symbiotic economic.

Through industry-university-research cooperation, universities and research institutes can bring into play the abundant innovative resource, which can greatly reduce the investment in research and development, shorten the cycle of industrialization, avoid duplication of investment and possible waste of resources. At the same time, enterprises can timely feed back market information to universities and research institutes who can have timely access to a wealth of practical information and experience, and enhance the targeted purpose discipline construction and professional development [8]. Then experts and professors of universities and research institutes can not only concentrate on research and development according to market demand, can also participate in the whole process of technological innovation including the new products and new technology's idea, project, research and development, batch test and marketing. They can extend the scientific research to the downstream, which can greatly improve the success rate and efficiency of technological innovation. From the theory of complementary resources, cooperative innovation can enhance enterprises' technological innovation capability and bring them a profit, at the same time, universities and research institutes can obtain the horizontal R \& D funding by offering services to enterprises, and channels and carriers of industrialization of scientific research provided by enterprises [9].

In conclusion, the U-I cooperation can effectively help SME overcome innovation consciousness insufficient, difficult to retain talent, lack of innovation capital and technology accumulation, poor of collaborative innovation. Moreover, through the promotion of knowledge transfer, accelerate the information flow, internalization of external talent, shared innovation resources, then strengthen the innovation of small and medium-sized enterprise resources, enhanced management ability, increased innovation tendency, heightened research and development ability, strengthened marketing ability, and then enhance the ability of technological innovation of SEM. Cooperative promotion of SEM mechanism model as shown below.

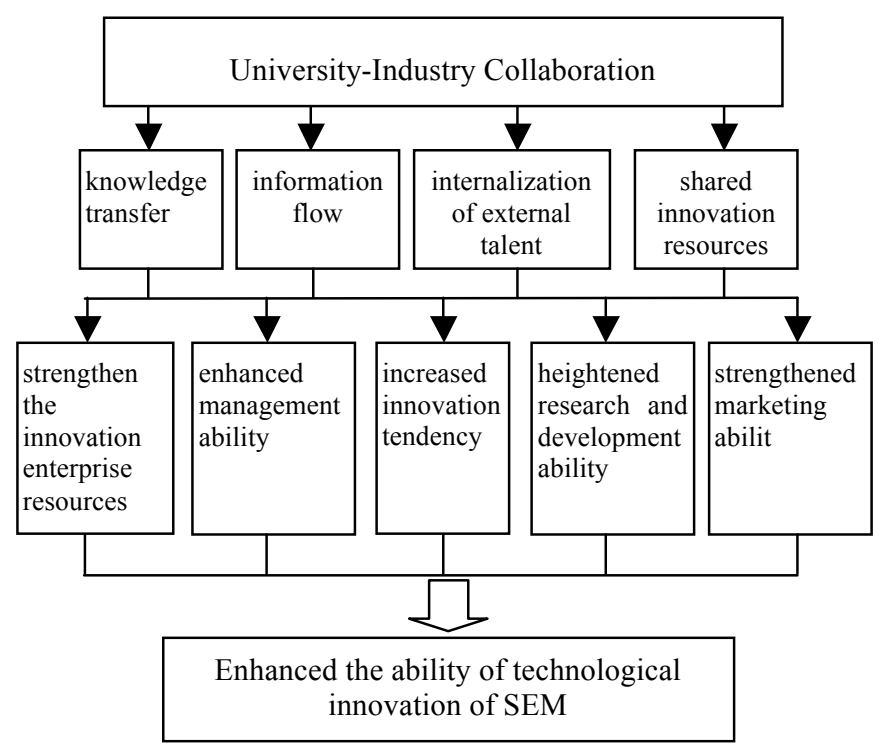

Fig. 1. Cooperative promotion model of technology innovation capability of SEM

\section{Conclusions}

In short, industry-university-research cooperation can promote enterprises together with universities and research institutes to carry on the joint technical research, build R \& $\mathrm{D}$ base, a high-tech enterprise, a science-technology park, establish strategic alliances based on long-term development goals. It helps SMEs to timely resolve the key technologies restricting the development of enterprises, acquire the latest scientific research results to meet their own needs so as to overcome the defects of its own R \& D capability and enhance the technological innovation capability and economic benefits. At the same time, it also enables universities and research institutes to select research direction from the industrial development, verify the R \& D results, and realize the market value of scientific research. During the process, they may get the funding voluntarily provided by enterprises or secure the support of the foundation to carry out scientific research and personnel training, and improve research capacity and level of teaching. To realize industry-university-research cooperation, however, it is far from enough to rely solely on the initiative of universities and enthusiasm of enterprises. Therefore, it is necessary to create the external macroenvironment to encourage and support industry-universityresearch cooperation, establish the relevant laws and regulations and policy system to encourage, support, motivate and ensure industry-university -research cooperation.

\section{Acknowledgements}

The research work was supported by provincial-level key project of Humanities and social science in colleges and universities of Anhui (SK2013A025). 


\section{References}

1. Archibugi, D., Coco, A. , "International partnerships for knowledge in business academia: a comparison between Europe and the USA", Technovation 24 (7), 2004,pp. 517-528.

2. Jia Z, Chao L., "Problems and Countermeasures in SMEs' independent innovation”, Market Modernization, 4, 2008, pp. 141142.

3. Zuoliang Yin, "An Empirical Analysis of the Technology Innovation Risk of Small and Medium Enterprise", Journal of Central University of Finance and Economics, 7, 2012, pp. 86-89.

4. M Bogers, "The open innovation paradox: knowledge sharing and protection in R\&D collaborations", European Journal of Innovation Management, 14(1), 2011, pp. 93-117.

5. Zhang Shanwei, "On How to Improve the Technological Innovative Ability of SMEs", Technology and Innovation Management, 30(2), 2009, pp. 144-146.
6. S Lee, G Park, B Yoon, J Park, "Open innovation in SEMs - An intermediated network model", Research Policy, 39(2), 2010, pp. 290-300

7. F Bougrain, B Haudeville, "Innovation, collaboration and SMEs internal research capacities", Research Policy, 31(5), 2002, pp. 735-747.

8. R Colomo-Palacios, Á García-Crespo, "A case analysis of semantic technologies for R\&D intermediation information management", International Journal of Management, 35(5), 2013, pp. 465-469.

9. SX Zeng, XM Xie, CM Tam, "Relationship between cooperation networks and innovation performance of SMEs",Technovation, 30(3), 2010, pp. 181-194 